OPEN ACCESS

Edited by:

Susumu Ohya,

Nagoya City University, Japan

Reviewed by:

lain A. Greenwood,

St George's, University of London, United Kingdom

Normand Leblanc,

University of Nevada,

Reno, United States

*Correspondence:

Clodagh Prendergast

c.prendergast@liverpool.ac.uk

Specialty section:

This article was submitted to Membrane Physiology and Membrane Biophysics, a section of the journal

Frontiers in Physiology

Received: 31 July 2021 Accepted: 24 September 2021

Published: 15 October 2021

Citation:

Wray S, Prendergast $C$ and Arrowsmith S (2021) Calcium-

Activated Chloride Channels in Myometrial and Vascular Smooth

Muscle.

Front. Physiol. 12:751008 doi: 10.3389/fphys.2021.751008

\section{Calcium-Activated Chloride Channels in Myometrial and Vascular Smooth Muscle}

\author{
Susan Wray ${ }^{1}$, Clodagh Prendergast ${ }^{1 *}$ and Sarah Arrowsmith ${ }^{2}$ \\ 'Department of Women and Children's Health, Institute of Life Course and Medical Sciences, University of Liverpool, \\ Liverpool, United Kingdom, ${ }^{2}$ Department of Life Sciences, Manchester Metropolitan University, Manchester, United Kingdom
}

In smooth muscle tissues, calcium-activated chloride channels ( $\mathrm{CaCC}$ ) provide the major anionic channel. Opening of these channels leads to chloride efflux and depolarization of the myocyte membrane. In this way, activation of the channels by a rise of intracellular $\left[\mathrm{Ca}^{2+}\right]$, from a variety of sources, produces increased excitability and can initiate action potentials and contraction or increased tone. We now have a good mechanistic understanding of how the channels are activated and regulated, due to identification of TMEM16A (ANO1) as the molecular entity of the channel, but key questions remain. In reviewing these channels and comparing two distinct smooth muscles, myometrial and vascular, we expose the differences that occur in their activation mechanisms, properties, and control. We find that the myometrium only expresses "classical," $\mathrm{Ca}^{2+}$-activated, and voltage sensitive channels, whereas both tonic and phasic blood vessels express classical, and non-classical, cGMP-regulated $\mathrm{CaCC}$, which are voltage insensitive. This translates to more complex activation and regulation in vascular smooth muscles, irrespective of whether they are tonic or phasic. We therefore tentatively conclude that although these channels are expressed and functionally important in all smooth muscles, they are probably not part of the mechanisms governing phasic activity. Recent knockdown studies have produced unexpected functional results, e.g. no effects on labour and delivery, and tone increasing in some but decreasing in other vascular beds, strongly suggesting that there is still much to be explored concerning $\mathrm{CaCC}$ in smooth muscle.

Keywords: calcium-activated chloride channels, vascular smooth muscle, myometrial smooth muscle, TMEM16A, Anoctamin 1, excitability, calcium, scramblases

\section{INTRODUCTION}

Chloride $\left(\mathrm{Cl}^{-}\right)$, its control, transport and contribution to fluid and volume control and excitability, is of long-standing interest to physiologists. It is abundant extracellularly in all cell types, at $\sim 100-110 \mathrm{mM}$, but of note, in smooth muscles, its concentration intracellularly is unusually high at $30-50 \mathrm{mM}$, due to the activities of $\mathrm{Cl}^{-} / \mathrm{HCO}_{3}^{-}$exchanger and $\mathrm{Na}^{+} \mathrm{K}^{+} \mathrm{Cl}^{-}$co-transporters. Consequently, when chloride channels open, chloride effluxes and the myocytes depolarize. In smooth muscles, there are volume-sensitive, bestrophins and CFTR chloride channels, but the most important, and the subject of this review, are $\mathrm{Ca}^{2+}$-activated chloride channels (CaCC). Unlike epithelial cells, in smooth muscle, $\mathrm{CaCC}$ are the major anion channel, but surprisingly 
much about CaCC remains enigmatic. Molecular and electrophysiological studies report CaCC properties that differ between tissues. By comparing two smooth muscles with different properties and regulatory mechanisms, myometrium and vascular, we will probe consistencies and differences in CaCCs. We will relate these findings to the functional roles and activation mechanisms of CaCCs. We start by summarising the background and current understanding of CaCCs, followed by an overview of the channels in smooth muscle, before moving on to the detailed review of them in myometrium and vascular smooth muscle (VSM).

\section{CaCC AND THE TMEM16 FAMILY}

Several reviews of $\mathrm{CaCC}$ composition, structure and regulation have been published and can be consulted for further details of the orientating overview we present here (Pedemonte and Galietta, 2014; Falzone et al., 2018; Kalienkova et al., 2021). The molecular identity of CaCC was established in 2008 (Caputo et al., 2008; Schroeder et al., 2008; Yang et al., 2008). TMEM16 were an orphan family of membrane proteins with 10 transmembrane domains (Brunner et al., 2014; Dang et al., 2017; Paulino et al., 2017a,b). This protein family was also called anoctamins, as they were thought to be anion-selective (An) and have eight (Oct) transmembrane domains. The topology and structure of $\mathrm{CaCC}$ are still being researched, but we know now, based on X-ray and cryo-EM data, that there are 10 , not eight, transmembrane domains (Brunner et al., 2014; Paulino et al., 2017a). There are 10 members of the TMEM16 family and all are $\mathrm{Ca}^{2+}$-activated. TMEM16A and TMEM16B (ANO1 and 2) are the only pure anion channels, i.e. CaCCs, in the family (Suzuki et al., 2013). They form dimers (Fallah et al., 2011), with each monomer activated by $\mathrm{Ca}^{2+}$, thus forming a double-barrelled channel (Jeng et al., 2016; Lim et al., 2016; Paulino et al., 2017a,b). Most, if not all these other members of the TMEM16 family function predominantly as phospholipid scramblases, which are important for maintaining bilayer symmetry and function. Although still controversial, it appears that the scramblases can also be non-selective ion channels conducting cations, and in some cases anions (Yang et al., 2012; Grubb et al., 2013; Shimizu et al., 2013; Kim et al., 2018; Lin et al., 2018). Interestingly, with regard to this, there has been suggestions about whether CaCCs permit a degree $(\sim 15-20 \%)$ of cation flux [see discussions in Picollo et al. (2015); Falzone et al. (2018)]. Liposome studies of the pure $\mathrm{CaCCs}$, however, show no dissipation of a $\mathrm{KCl}$ gradient supporting anion selectivity, as does the positive shift in reversal potential when $\mathrm{SCN}^{-}$is substituted for $\mathrm{Cl}^{-}$in the extracellular medium (Ferrera et al., 2011; Paulino et al., 2017a). It has been shown

\footnotetext{
Abbreviations: AP, action potential; SMC, smooth muscle cell; VSM, vascular smooth muscle; $\mathrm{CaCC}, \mathrm{Ca}^{2+}$-activated chloride channel; $\mathrm{PIP}_{2}$, phosphatidylinositol 4,5-bisphosphate; LTCC, L-type $\mathrm{Ca}^{2+}$ channel; MLCK, myosin light chain kinase; PLC, phospholipase C; DAG, diacylglycerol; TMEM16A, ANO, anoctamin; SR, sarcoplasmic reticulum; STIC, spontaneous transient inward current; STOC, spontaneous transient outward current; CaMKII, $\mathrm{Ca}^{2+}$-calmodulin kinase II.
}

that single point mutations of the pore will greatly decrease anion selectivity and increase cationic (Yang et al., 2008, 2012; Peters et al., 2018). To explain this, it has been suggested that the $\mathrm{CaCC}$ channel has voltage-dependent conformational changes which may allow it to conduct cations (Peters et al., 2018). The details of the pharmacological and biophysical properties of native CaCCs vary depending on the tissues under study, possibly due to splice variations, heterodimers or even association of different subunits. Splicing leads to multiple isoforms and can have significant effects on channel function, such as changing $\mathrm{Ca}^{2+}$ sensitivity (Ferrera et al., 2009). Recently allosteric modulation of splice variants of $\mathrm{CaCC}$ by phosphatidylinositol 4,5-bisphosphate $\left(\mathrm{PIP}_{2}\right)$ and CaMKII has been reported, adding to the complexity of channel regulation (Ko et al., 2020).

\section{CALCIUM-ACTIVATED CHLORIDE CHANNELS ARE PRESENT IN SMOOTH MUSCLES}

Before the molecular identification of CaCC (Caputo et al., 2008; Schroeder et al., 2008; Yang et al., 2008), the presence of a $\mathrm{Ca}^{2+}$-activated $\mathrm{Cl}^{-}$current $\left(\mathrm{I}_{\mathrm{ClCa}}\right)$ had been identified in SMCs, and functional studies conducted. Electrophysiological studies demonstrated slow (relative to L-type $\mathrm{Ca}^{2+}$ currents), voltage-dependent (at submaximal $\left[\mathrm{Ca}^{2+}\right]$ ), $\mathrm{Ca}^{2+}$-activated current, with outward rectification and corresponding functional studies showed depolarization and contraction [see (Large and Wang, 1996) for an excellent review of this early literature and (Janssen and Sims, 1992; Akbarali and Giles, 1993; Greenwood et al., 1995)]. A variety of not-so-specific CaCC inhibitors, including niflumic acid (NFA), 9-AC (9-Anthracenecarboxylic acid) and DIDS, (4,4'-Diisothiocyano-2,2'-stilbenedisulfonic acid), blocked the current, produced hyperpolarisation and relaxed smooth muscles (Large and Wang, 1996). L-type $\mathrm{Ca}^{2+}$ channels (LTCC) represent the major pathway for the increase in $\mathrm{Ca}^{2+}$ needed for contraction in smooth muscles, but CaCCs can provide a positive feedback mechanism in the myocytes, as they are activated by the $\mathrm{Ca}^{2+}$ entry, and help to maintain depolarization as $\mathrm{Cl}^{-}$effluxes through their pore.

The channels and currents have been found in all smooth muscle tissues, indicating an important functional role [Urethra (Drumm et al., 2021); bladder (Kajioka et al., 2004; Bijos et al., 2014); ureter (Iqbal et al., 2012; Hunziker et al., 2020); airway (Kotlikoff and Wang, 1998; Gallos et al., 2013); GI tract (Sanders et al., 2012); and oesophagus (Saha et al., 1992; Akbarali and Giles, 1993; Zhang and Paterson, 2002)]. There are, however, some key areas of uncertainty. With particular relevance to smooth muscles, (1) is the source of activating $\mathrm{Ca}^{2+}$ coming from the extracellular entry of $\mathrm{Ca}^{2+}$ (L-type and possibly TRP channels) or intracellular stores, i.e. the sarcoplasmic reticulum (SR) or mitochondria?, (2) is channel activation directly by $\mathrm{Ca}^{2+}$ or indirectly via a $\mathrm{Ca}^{2+}$-activated intermediary, e.g. calmodulin-activated kinases, and (3) are expression and functional effects in some smooth muscle tissues due to interstitial cells of Cajal (ICC), not myocytes, 
expressing the $\mathrm{CaCC}$ and passing the depolarization via gap junctions to the myocytes?

By comparing two types of smooth muscle, one spontaneous and phasic, and one tonic, we asked whether the answers to these three questions differed by type, but also if there was support for the suggestion that the contribution of $\mathrm{CaCC}$ to excitability also differed.

\section{CALCIUM-ACTIVATED CHLORIDE CHANNELS IN MYOMETRIUM}

The myometrium is a spontaneously active (myogenic) smooth muscle. The processes leading to cell activation and contraction are complex and involve the activity of several ion channels to promote a change in membrane potential $\left(\mathrm{V}_{\mathrm{m}}\right)$. The resting $\mathrm{V}_{\mathrm{m}}$ of pregnant myocytes is around $-60 \mathrm{mV}$ which shifts to $-40 \mathrm{mV}$ towards term in rodents and humans (Parkington et al., 1999) in line with myometrial transition from quiescence during pregnancy to an actively contracting organ in labour. As is the case in other SMCs, membrane depolarization results in activation of L-type, voltage-gated $\mathrm{Ca}^{2+}$ channels (LTCCs) to provide calcium entry and action potential (AP) generation. The accompanying rise in $\left[\mathrm{Ca}^{2+}\right]_{i}$ gives rise to contraction, and oscillations in $\mathrm{V}_{\mathrm{m}}$ give rise to rhythmic contractions (Figure 1A).

The identity of the channel/s (and ions) responsible for the initial depolarisation to reach the threshold needed for LTCC activation is unknown. However, CaCCs have been implicated in carrying this current (Wray et al., 2015; Wray and Arrowsmith, 2021).

The presence of $\mathrm{Cl}^{-}$currents in the myometrium was first described by Parkington and Coleman in single channel recordings in intact tissue strips of guinea-pig myometrium (Coleman and Parkington, 1987). $\mathrm{A} \mathrm{Cl}^{-}$current induced by oxytocin was also observed by Arnaudeau in rat myometrial cells following short-term culture (Arnaudeau et al., 1994). Later, our group, using freshly isolated rat myometrial cells, showed that this channel was activated by calcium entering via LTCC (Jones et al., 2004). The current was present in one-third of cells as a slowly deactivating tail current which was observed upon repolarisation following stepwise depolarisation. A tail current is the current remaining after the initial depolarizing stimulus has been removed and is an indicator of the timing of channel closures. That a tail current was observed following repolarisation when the LTCC are closed and L-type $\mathrm{Ca}^{2+}$ current would be inactive, suggested other channel species were present, open and carrying this late inward current. The current's reversal potential was found to be close to that of $\mathrm{Cl}^{-}$and was sensitive to $\left[\mathrm{Cl}^{-}\right]$. Moreover, it was sensitive to $\mathrm{Ca}^{2+}$ but not $\mathrm{Ba}^{2+}$ and was enhanced by the LTCC agonist, BayK8644 (Jones et al., 2004).

In addition to $\mathrm{Ca}^{2+}$ entry, other sources of activating $\mathrm{Ca}^{2+}$ could include that from the SR, either via local $\mathrm{Ca}^{2+}$ sparks from the spontaneous opening of Ryanodine receptors (RyR) or from a more global rise in $\mathrm{Ca}^{2+}$ via agonist-mediated $\mathrm{IP}_{3}$ release. However, calcium sparks do not occur in myometrium
(Burdyga et al., 2007) and the RyRs are non-functional (Dabertrand et al., 2007). $\mathrm{IP}_{3}$ receptors are present and oxytocin is associated with activation of CaCCs (Arnaudeau et al., 1994). In cultured mouse myometrial cells, an inward current was recorded, which was blocked by $\mathrm{CaCC}$ inhibitors (Bernstein et al., 2014). The inhibitors also reduced agonist-mediated increases in $\mathrm{Ca}^{2+}$ and the authors suggested that SR release can also assist channel opening in myometrium (Bernstein et al., 2014). But whether SR $\mathrm{Ca}^{2+}$ release is a requirement for channel activation was not determined. As $\mathrm{Ca}^{2+}$ entry in the absence of an agonist was shown to activate CaCCs, Jones et al. concluded that L-type $\mathrm{Ca}^{2+}$ entry was the source of activating $\mathrm{Ca}^{2+}$. A similar logic would also hold for other intracellular organelles, such as mitochondria, but this has not been directly investigated.

Whether functional CaCC or other TMEM16 family members are present intracellularly, e.g. on SR or mitochondria is a controversial area but such expression has been reported in human myometrium (Pedemonte and Galietta, 2014; Danielsson et al., 2018). Whether there is a functionally important role for these channels within the SR or if their presence is simply due to protein processing and trafficking is not known.

Following the identification of TMEM16A and B (ANO1/2) and the development of TMEM16 A and B-selective inhibitors, their function as the putative CaCCs in myometrium has been studied. Both are expressed in human and rodent myometrium (Bernstein et al., 2014; Danielsson et al., 2015). Pharmacological inhibition of TMEM16A and B eliminated inward currents in patched mouse myometrial cells (Bernstein et al., 2014), produced hyperpolarisation in immortalised human myometrial cells [measured indirectly using a fluorescent potentiometric indicator and induced relaxation in human myometrial strips precontracted with oxytocin (Danielsson et al., 2018; Hyuga et al., 2018)]. siRNA knockdown of TMEM16A in primary or human myometrial cells also resulted in an attenuation of the oxytocininduced increase in filamentous to globular actin ratio which is a marker of actin polymerisation and indicator of cell contraction (Danielsson et al., 2018). The findings from this group, albeit somewhat indirect and not on fresh myocytes, add to the suggestions of TMEM16A contributing to myometrial excitability.

\section{CaCC Function in Myometrium}

That CaCCs are both voltage-gated and activated by increases in $\left[\mathrm{Ca}^{2+}\right]_{i}$, makes them suitable candidates for participating in excitation-contraction coupling and AP generation in myometrium. The activation of $\mathrm{CaCC}$ will depolarize or maintain depolarization of the myometrial membrane, increase excitability and the open probability of LTCC, and AP generation. In this way, $\mathrm{CaCCs}$ in the myometrium are likely to contribute to both spontaneous and oxytocin-stimulated contractions with the latter thought to also involve $\mathrm{IP}_{3}$-mediated release of $\mathrm{Ca}^{2+}$ from the SR (Figure 1A).

The frequency, amplitude and duration of contractions have long been associated with the frequency and duration of AP firing (Burdyga et al., 2007, 2009). In rat myometrial tissues, CaCCs have also been implicated in stabilising the plateau 


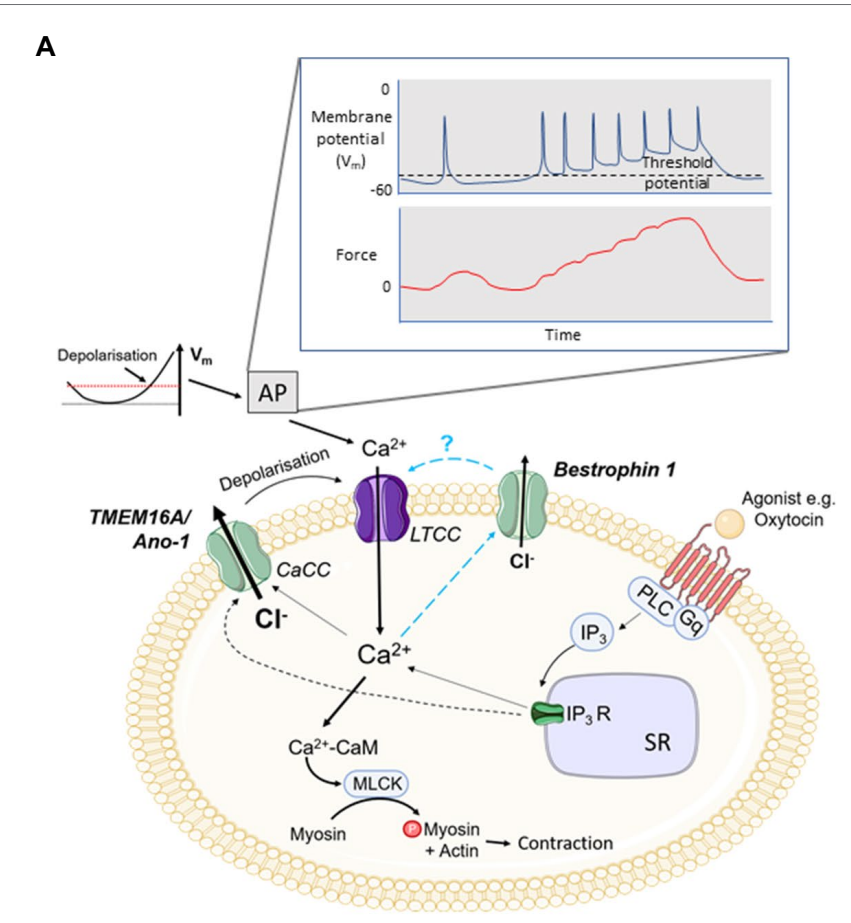

Myometrial cell

(spontaneous phasic contractions)
B

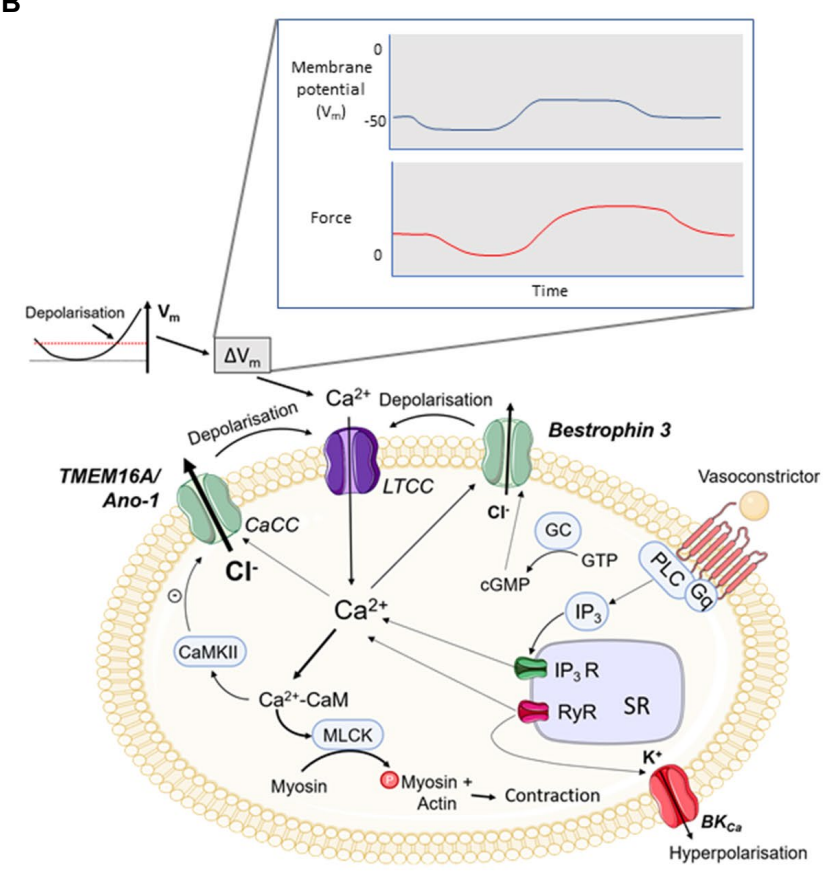

Vascular smooth muscle cell (tonic contractions)

FIGURE 1 | Excitation-contraction coupling in uterine and vascular smooth muscle cells (VSMCs) and the potential roles for CaCCs. (A) In spontaneously active smooth muscles, e.g. myometrium, depolarisation of the membrane potential $\left(V_{m}\right)$ to threshold initiates an action potential (AP) and phasic contractions. (B) In most vascular smooth muscles which are not spontaneously active, slow, tonic changes in $V_{m}$ give rise to tonic contractions. In both, depolarisation leads to opening of voltage-gated calcium channels (L-Type, LTCC) and calcium entry. Calcium binds to calmodulin and the Ca ${ }^{2+}$-CaM complex activates myosin light chain kinase, MLCK. MLCK phosphorylates myosin promoting actin and myosin cross-bridge formation and contraction. Agonists, such as oxytocin in the myometrium (A) or vasoconstrictors in VSMCs (B), binding to their receptor activate PLC which in turn hydrolyses $P_{2} P_{2}$ to $I_{3}$ and $D A G$ (not shown). IP 3 binds to its receptor, $\mathrm{PP}_{3} R$, on the SR and facilitates $\mathrm{Ca}^{2+}$ efflux into the cytoplasm. The rise in $\left[\mathrm{Ca}^{2+}\right]_{\mathrm{i}}$ is thought to activate calcium-activated chloride channels $(\mathrm{CaCC}$; TMEM16A/ANO-1 in myometrium and TMEM16AVANO-1 and Bestrophin 3 in VSMCs), producing a chloride efflux, depolarisation of the cell membrane and opening of LTCCs. In myometrium, activation of CaCCs may be responsible for the initial depolarisation required to activate LTCCs. Ca ${ }^{2+}$ entry via LTCCs may also facilitate the opening of CaCCs which further increases the open probability of LTCC opening. The role of Bestrophins in excitation-contraction coupling in myometrium is not known. Additionally, in VSMCs, spontaneous calcium release through RyRs (Ca ${ }^{2+}$ sparks) on the SR can also contribute to CaCC opening (STICs) and depolarisation. Ca ${ }^{2+}$ sparks also activate $\mathrm{BK}_{\mathrm{Ca}}$ leading to $\mathrm{K}^{+}$efflux, STOCs and hyperpolarisation. Bestrophin channels are positively regulated by cGMP and TMEM16A/ANO1 channels are inhibited by CaMKII. Ca ${ }^{2+}$ entry via store - operated $\mathrm{Ca}^{2+}$ entry and via TRPC6 channels can also stimulate CaCC current and depolarisation (not shown).

phase of the AP and being responsible for prolonging the duration of contraction (Young and Bemis, 2009). A role for CaCCs in establishing or contributing to cell excitability is further supported by the reduced frequency of contraction following the application of several CaCC inhibitors (Yarar et al., 2001; Kaya et al., 2002; Jones et al., 2004; Bernstein et al., 2014; Danielsson et al., 2018; Hyuga et al., 2018). As mentioned previously, some CaCC blockers are non-specific, and off-target actions may synergise with their inhibition of $\mathrm{CaCC}$ to produce myometrial relaxation (tocolysis).

Interestingly, $\mathrm{I}_{\mathrm{ClCa}}$ was only present in around one-third of freshly isolated rat myometrial cells (Jones et al., 2004), and only $5 \%$ of cultured murine cells showed auto-rhythmicity (Bernstein et al., 2014). This suggests that those cells expressing $\mathrm{CaCC}$ could be the pacemakers or electrogenic cells in the myometrium, equivalent to the ICC cells in gastric smooth muscle. Modelling of excitation-contraction coupling events by integrating transcriptomic data with electrophysiological data also supports a role for CaCCs in generating spontaneous depolarisations (Atia et al., 2016). Tantalising as these data are, direct evidence that $\mathrm{CaCC}$ are a major contributor to pacemaking and spontaneous activity in myometrium is lacking. Furthermore, TMEM16A expression was found to be downregulated (15-fold) in late gestation (non-labouring) pregnant human myometrium compared to non-pregnant (Danielsson et al., 2018). This reduced expression may reflect that the uterus is in a state of quiescence required to maintain pregnancy. Alternatively, TMEM16A channels may not be as important as suggested; SMC-specific deletion of TMEM16A in pregnant mice did not alter calcium signalling, uterine contraction or change the length of gestation (Qu et al., 2019), which casts doubt on the importance of the channel in myometrial physiology and its role in pacemaking for spontaneous, or as a depolarising channel for agonist-induced contractions. However, the extent of the reduction in TMEM16A in these conditional knockout mice is not clear. 
Other channels known to display $\mathrm{Ca}^{2+}$ sensitivity and conduct $\mathrm{Cl}^{-}$include Bestrophins (BEST 1, 2 and 3). Unlike TMEM16A/ ANO1, however, they are not voltage sensitive. In expression systems, BEST-1 has been shown to modulate the LTCC current (Reichhart et al., 2010) by interacting with the channel's $\beta$-subunits and regulating the number of pore forming subunits (Milenkovic et al., 2011). Its combined role as a $\mathrm{Ca}^{2+}$-dependent anion channel and regulator of LTCCs is thought to provide a feedback mechanism to control $\mathrm{Ca}^{2+}$-dependent $\mathrm{Cl}^{-}$transport (Milenkovic et al., 2011). BEST-3 is a CaCC, which displays cGMP dependence [see later, Matchkov et al. (2008)]. BEST-1 is expressed in non-pregnant rat myometrium (Mijuskovic et al., 2015) and inhibition of bestrophins using DIDS has been implicated in mediating the relaxatory effect of hydrogen sulphide in myometrium (Mijuskovic et al., 2015). Their role in excitation-contraction coupling in myometrium, however, has not been studied.

Questions that remain unanswered include whether there is upregulation of TMEM16A or B in labour in humans to facilitate a pro-contractile drive, or similarly, whether expression and/or function of the channel is altered in preterm labour, and whether its inhibitors relax the labouring uterus. This is particularly important if they are to be used as targets for tocolysis - a major goal of the research in this area. Of note, both intra and extracellular protons have been shown to regulate TMEM16A activity (Cruz-Rangel et al., 2017): raising extracellular protons and subsequent channel protonation increase TMEM16A activation without changing their $\mathrm{Ca}^{2+}$ sensitivity. During contractions, the myometrium undergoes transient acidification (Larcombe-Mcdouall et al., 1999), which we have shown increases myometrial activity (Pierce et al., 2003; Alotaibi et al., 2015). Could CaCCs therefore, contribute to the stimulation seen under extracellular acidic conditions in labour?

\section{SUMMARY}

In myometrium, TMEM16A CaCC are expressed. We conclude that (1) L-type $\mathrm{Ca}^{2+}$ entry is the major source of activating calcium, (2) that this activation is direct, and (3) their expression is on myocytes, but only a subset of those present. More direct studies on labouring and non-labouring myometrium are urgently needed.

\section{CALCIUM-ACTIVATED CHLORIDE CURRENTS IN VSM}

Most VSM exists in a state of partial contraction (myogenic tone) from which it can dilate or constrict according to physiological requirements. There are some exceptions, such as portal vein, which exhibit spontaneous phasic contractions. Here, we will concentrate primarily on tonically contracting vessels as a comparison to the spontaneously active myometrial SM. However, as important work has been carried out in the phasic portal vein (which is arterial to the liver), and data on myometrium are limited, where relevant we will discuss data on both types of VSM and compare to the myometrium.

$\mathrm{Ca}^{2+}$-activated $\mathrm{Cl}^{-}$currents $\left(\mathrm{I}_{\mathrm{CICa}}\right)$ were first reported in VSM cells isolated from guinea-pig pulmonary artery (Byrne and Large, 1987). Since then, $I_{\text {CICa }}$ has been identified in many different tonic vessels (e.g. aorta, coronary, pulmonary, cerebral and mesenteric arteries) from multiple species (Lamb et al., 1994; Large and Wang, 1996; Davis et al., 2010, 2013; Manoury et al., 2010; Thomas-Gatewood et al., 2011; Matchkov et al., 2013; Dam et al., 2014; Cil et al., 2021). The currents have also been shown in spontaneously active vessels, e.g. in rabbit portal vein (Byrne and Large, 1988) and guinea-pig mesenteric vein (Van Helden, 1991).

The tail current amplitude varies between vessels and species: $\mathrm{I}_{\mathrm{CICa}}$ is large in conduit vessels (tail current density $40 \mathrm{pA} / \mathrm{pF}$ ) and very large in the pericytes of the microvasculature $(130 \mathrm{pA} /$ $\mathrm{pF})$, but small $(5-10 \mathrm{pA} / \mathrm{pF})$ or absent in small arteries of the mouse (Heinze et al., 2014). However, other studies have identified these currents in rat, rabbit and human small arteries $[5-10 \mathrm{pA} / \mathrm{pF}$ in rabbit pulmonary and coronary arteries (Greenwood et al., 2001) and $20 \mathrm{pA} / \mathrm{pF}$ in rat cerebral arteries (Thomas-Gatewood et al., 2011)], although current density was not shown in all (Klockner and Isenberg, 1991; Thomas-Gatewood et al., 2011; Dam et al., 2014). In myometrium, the amplitude of the tail current was $162 \pm 48 \mathrm{pA}$ in rat myocytes, equivalent to a current density of approx. $1.5 \mathrm{pA} / \mathrm{pF}$ (Jones et al., 2004), which is small compared to the current in the SM of conduit vessels and microvessels. A similarly small peak current density of $5 \mathrm{pA} / \mathrm{pF}$ was recorded in murine portal vein (Ohshiro et al., 2014). In spontaneously active venous tissues, spontaneous depolarizations are observed that have been linked to $\mathrm{I}_{\mathrm{CICa}}$ (Van Helden, 1991). ICC-like cells have been identified in portal vein (Povstyan et al., 2003; Huang et al., 2010), but it is not clear whether they act as pacemaker cells, as SMC also generate spontaneous depolarizations. Interestingly, it was found that $40 \%$ of portal vein myocytes express an $\mathrm{I}_{\mathrm{CICa}}$ compared to $90 \%$ of myocytes from the tonic pulmonary and coronary arteries (Greenwood et al., 2001), an expression difference perhaps linked to the differential nature of a tonic vessel and spontaneously active vessel with pacemaker activity.

\section{CaCC Identity in VSM}

TMEM16A/ANO1 has been identified as the 'classical' CaCC in VSM and TMEM16A mRNA and protein are widely expressed (Davis et al., 2010; Manoury et al., 2010; Thomas-Gatewood et al., 2011). Inhibition of CaCC by traditional non-selective blockers [e.g. NFA (Criddle et al., 1996, 1997; Kamouchi et al., 1997; Sun et al., 2012)] or more recent selective inhibitors [e.g. $\mathrm{T}_{16 \mathrm{~A}_{\text {inh }}} \mathrm{A} 01$ and $\mathrm{TM}_{\mathrm{inh}}-23$ (Davis et al., 2010, 2013; Cil et al., 2021)] leads to vasorelaxation of tonic VSM. siRNA knockdown of TMEM16A also reduces arterial constriction (Bulley et al., 2012; Dam et al., 2014; Heinze et al., 2014; Jensen et al., 2018).

Multiple splice variants of TMEM16A have been identified in murine thoracic aorta, carotid artery and portal vein (Davis et al., 2010; Ohshiro et al., 2014). Splice variants can exhibit 
differing $\mathrm{Ca}^{2+}$ sensitivities and voltage-dependence (Ferrera et al., 2009). In portal vein, Ohshiro and co-workers (Ohshiro et al., 2014) have demonstrated the ability of splice variants to homo and hetero-dimerize. Varied co-expression of splice variants and homo/heterodimerization of channels provides great scope for diversity of physiological functioning of $\mathrm{CaCC}$ across different vascular beds.

Many VSMs also co-express a second $\mathrm{Ca}^{2+}$-dependent $\mathrm{Cl}^{-}$ conductance that is distinct from the classical $\mathrm{I}_{\mathrm{ClCa}}$, in that it requires cGMP for activation, is not voltage-dependent and is resistant to inhibition by NFA (Matchkov et al., 2005). Both channels co-exist, but relative distribution varies along the vascular tree (Matchkov et al., 2005). This $\mathrm{I}_{\mathrm{Cl}(\mathrm{cGMP}, \mathrm{Ca})}$ current is encoded by bestrophin 3, rather than the TMEM16A/ANO1 gene, since knockdown of the bestrophin gene leads to disappearance of the cGMP-dependent chloride current, but not the classical $\mathrm{I}_{\mathrm{ClCa}}$ current (Matchkov et al., 2008; Broegger et al., 2011). $\mathrm{I}_{\mathrm{Cl}(\mathrm{cGMP}, \mathrm{Ca})}$ does not mediate agonist-stimulated contraction but instead plays a role in regulation of tissue perfusion by mediating tone oscillations in VSM (Boedtkjer et al., 2008; Broegger et al., 2011). Both cGMP-dependent and classical $\mathrm{I}_{\mathrm{CICa}}$ currents are expressed in spontaneously active portal vein (Matchkov et al., 2005). This differs from myometrium, where only classical $\mathrm{CaCC}$ are expressed and BEST-3 has not been reported, but BEST-1 has (Mijuskovic et al., 2015). Thus, $I_{\text {ClCagmp }}$ is a feature of VSM - irrespective of it being phasic or tonic.

\section{CaCC Function in VSM}

Similar to myometrium and other SM, CaCC play a role in excitation-contraction coupling in VSM cells (Large and Wang, 1996). The $\mathrm{Ca}^{2+}$ required to activate $\mathrm{CaCC}$ in tonic VSM can come from multiple sources including extracellular and agonist(e.g. vasoconstrictor) mediated SR release (Figure 1B). Compared to myometrium, in VSM, the mechanisms that have been shown to activate $\mathrm{CaCC}$ are more varied. Depolarising currents that activate $\mathrm{Ca}^{2+}$ entry via LTCC trigger $\mathrm{I}_{\mathrm{ClCa}}$, either directly [coronary artery (Lamb et al., 1994), renal artery (Gordienko et al., 1994)] or by stimulating $\mathrm{Ca}^{2+}$-induced $\mathrm{Ca}^{2+}$ release via $\mathrm{RyR}$ (Lamb et al., 1994). Agonist-mediated release of $\mathrm{Ca}^{2+}$ from the SR [pulmonary artery (Helliwell et al., 1994; Yuan, 1997)] is another important route by which $\mathrm{I}_{\mathrm{ClCa}}$ is activated. $\mathrm{Ca}^{2+}$ entry via store-operated $\mathrm{Ca}^{2+}$ entry (SOCE) [pulmonary artery (Forrest et al., 2010; Angermann et al., 2012)] and via TRPC6 channels [cerebral artery (Wang et al., 2016)] can also stimulate CaCC current and depolarisation.

In VSM, the spontaneous release of $\mathrm{Ca}^{2+}$ from the SR via RyRs $\left(\mathrm{Ca}^{2+}\right.$ sparks) is associated with stimulation of $\mathrm{Ca}^{2+}$-activated channels on the sarcolemma. When large-conductance $\mathrm{Ca}^{2+}$ dependent $\mathrm{K}^{+}$channels $\left(\mathrm{BK}_{\mathrm{Ca}}\right)$ are activated in this way, spontaneous transient outward currents (STOCs) are generated, and hyperpolarisation and vasodilation ensue (Nelson et al., 1995). When CaCC are activated, spontaneous transient inward currents (STICs) occur and cause depolarisation and vasoconstriction, thus playing a role in determining vasomotor tone. The balance between these two pathways varies from vessel to vessel and will determine the overall contractility of the VSM [cerebral artery (Zhao et al.,
2017) and renal arterioles (Yip et al., 2018)]. $\mathrm{Ca}^{2+}$ sparks and associated CaCC-mediated STICs have been identified in both tonic and phasically contracting VSMs (Wang et al., 1992; Large and Wang, 1996; Yip et al., 2018).

Diverse sources of $\mathrm{Ca}^{2+}$ activate $\mathrm{I}_{\mathrm{ClCa}}$ in the spontaneously active portal vein preparation [L-type $\mathrm{Ca}^{2+}$ entry, agonist-induced SR $\mathrm{Ca}^{2+}$ release and spontaneous release of $\mathrm{Ca}^{2+}$ from the SR (sparks) and reverse mode sodium-calcium exchange (NCX)] (Wang et al., 1992; Leblanc and Leung, 1995; Greenwood and Large, 1996; Burt, 2003; Saleh and Greenwood, 2005). In contrast, few mechanisms of $\mathrm{I}_{\mathrm{ClCa}}$ activation have been identified in the spontaneously active myometrial smooth muscle (Figure 1A). As mentioned above, in the myometrium, $\mathrm{Ca}^{2+}$ sparks are not found and RyRs are non-functional. Nor have the role of NCX, SOCE, TPRC6 been determined in relation to CaCC activation.

In addition to mediating the response to contractile agonists, $\mathrm{CaCC}$ are involved the vascular myogenic response. CaCC antagonists or TMEM16A knockdown hyperpolarises and dilates vessels (Nelson et al., 1997; Bulley et al., 2012; Yip et al., 2018) and reducing extracellular $\mathrm{Cl}^{-}$augments myogenic tone (Doughty and Langton, 2001). CaCC are also implicated in the generation of vasomotion (Boedtkjer et al., 2008; Dam et al., 2014) and spontaneous contraction of portal vein (Wang et al., 1992).

Vascular smooth muscle-specific disruption of TMEM16A/ ANO1 in mice abolished $\mathrm{I}_{\mathrm{ClCa}}$ in VSM of the aorta, carotid artery and small arterioles of the brain and retina and resulted in lowering of blood pressure (Heinze et al., 2014). This hypotensive effect is likely mediated via small diameter arterioles, where many $\mathrm{CaCC}$ are expressed and the vasocontractility they mediate will affect peripheral resistance. In the spontaneously hypertensive rat, TMEM16A/ANO1 is overexpressed in aorta, carotid, mesenteric and hind limb arteries (Wang et al., 2015). siRNA knockdown or pharmacological inhibition of these channels prevented hypertension development in this model (Wang et al., 2015). In addition, TMEM16A expression and activity are significantly upregulated in various pulmonary hypertension models (Forrest et al., 2012; Sun et al., 2012; Papp et al., 2019). However, in an alternative model of hypertension, the 2 kidney 2 clip model, TMEM16A expression and $\mathrm{I}_{\mathrm{ClCa}}$ are reduced and $\mathrm{CaCC}$ activity is negatively correlated with blood pressure and medial cross-sectional area of the basilar artery (Wang et al., 2012), suggesting that downregulation of $\mathrm{CaCC}$ is associated with the cerebrovascular remodelling that occurs during hypertension.

In a recent study of heterozygous TMEM16A/ANO1 knockout mice, a $50 \%$ decrease in $\mathrm{I}_{\mathrm{ClCa}}$ reduced aortic contractility as expected, but paradoxical increases in tail/saphenous artery contractility were observed (Matchkov et al., 2020). Clearly the in vivo functional role of $\mathrm{CaCC}$ is complicated and requires further examination.

\section{Regulation of Classical CaCC in VSM}

TMEM16A/ANO1 channels are gated by $\mathrm{Ca}^{2+}$, but sustained $\mathrm{Ca}^{2+}$-activation induces desensitisation. When TMEM16A is expressed in HEK293T cells, $\mathrm{PIP}_{2}$ is required for channel 
activation and guards against $\mathrm{Ca}^{2+}$-induced inactivation (Arreola and Hartzell, 2019; Le et al., 2019). This means that agonistinduced $\mathrm{IP}_{3}$ production on the one hand activates $\mathrm{CaCC}$, but simultaneously $\mathrm{PIP}_{2}$ hydrolysis reduces the availability of $\mathrm{PIP}_{2}$ and reduces channel opening. Similar findings were reported in detrusor SMCs (Yarotskyy et al., 2019); however, the only study to examine the role of $\mathrm{PIP}_{2}$ in VSM found that $\mathrm{PIP}_{2}$ tonically inhibits CaCC (Pritchard et al., 2014). Further investigations are required to determine whether $\mathrm{PIP}_{2}$ is inhibitory in all VSM and why the mechanism differs between cell types.

Phosphorylation by $\mathrm{Ca}^{2+}$-calmodulin-dependent kinase II (CaMKII) attenuates activation of CaCC in a variety of VSMs (Greenwood et al., 2001; Wiwchar et al., 2009). This represents another important negative feedback mechanism whereby vasoconstricting agonists can limit the depolarising influence of CaCC. Calmodulin mediates the $\mathrm{Ca}^{2+}$-dependent inactivation of TMEM16A (Yang et al., 2014; Yang and Colecraft, 2016) but not its activation. Since phosphorylation inactivates $\mathrm{CaCC}$, phosphatases, such as calcineurin, PP1 and PP2, can enhance channel function (Ledoux et al., 2003; Ayon et al., 2009).

Although TMEM16A expression is relatively evenly spread across the VSM sarcolemma (Davis et al., 2010), it is suggested that TMEM16A are to some extent localised to lipid microdomains, as the amplitude and pharmacology of $\mathrm{I}_{\mathrm{ClCa}}$ are significantly altered by cholesterol depletion with methyl$\beta$-cyclodextrin (Sones et al., 2010), although this has only been studied in mouse portal vein thus far. There is an intriguing overlap in pharmacology between $\mathrm{BK}_{\mathrm{Ca}}$ channels and CaCC (Greenwood and Leblanc, 2007), which may be partly related to their co-localisation in lipid rafts given a loss of shared pharmacology after cholesterol depletion (Sones et al., 2010), although it is likely more complicated than simple co-localisation.

As mentioned earlier, changes in $\mathrm{pH}$ affect channel activity (Cruz-Rangel et al., 2017) and in smooth muscles, this may lead to changes in cell excitability. In pulmonary artery myocytes, chronic hypoxia, which will also change $\mathrm{pH}$, strongly increases TMEM16A expression and CaCC currents, which may be the cause of the enhanced serotonin-mediated vasoreactivity associated with pulmonary hypertension (Sun et al., 2012).

\section{Comparison of Tonic and Phasic Smooth Muscles}

We have described $\mathrm{CaCC}$ expression, function and regulation in two very different smooth muscles: the myometrium and tonic VSMs, with some comparisons made to spontaneously active VSM. Returning to the questions we posed at this start of this review, in relation to the source of CaCC-activating $\mathrm{Ca}^{2+}$, there appears to be genuine, rather than experimental differences between smooth muscles, e.g. in uterus, L-type $\mathrm{Ca}^{2+}$ entry is the activator, whereas in blood vessels, $\mathrm{SR} \mathrm{Ca}{ }^{2+}$ release through RyRs (and other alternative sources, e.g. SOCE) is also important. In myometrium, any $\mathrm{SR} \mathrm{Ca}^{2+}$ activating the CaCCs will be from agonist-mediated release through $\mathrm{IP}_{3} \mathrm{Rs}$. Other smooth muscles not discussed in this review also show these differences [e.g. urethra (Drumm et al., 2018)].
Whether channel activation is directly by $\mathrm{Ca}^{2+}$ or via an intermediary, e.g. CaM kinase II, has been a controversial area. Evidence to support direct binding of $\mathrm{Ca}^{2+}$ activating the channel has come from expression of human TMEM16A in liposomes (Terashima et al., 2013), in which all the properties of CaCC, including $\mathrm{Ca}^{2+}$ sensitivity, were recapitulated in the absence of calmodulin. The review Yang and Colecraft (2016) concluded that 'there is now overwhelming evidence that $\mathrm{Ca}^{2+}$-dependent activation occurs through $\mathrm{CaCC}$ binding directly to the channel, and does not require CaM'. In fact, phosphorylation by CaMKII attenuates activation of $\mathrm{CaCC}$ in many VSMs (Greenwood et al., 2001; Wiwchar et al., 2009) and to date, such regulation has not been studied in myometrium.

In phasic smooth muscles, a major question is around the identity of the cells expressing and conducting the $\mathrm{CaCC}$ current. In the GI tract, CaCC channel expression and pacemaking activity are exclusively in the ICC cells and in urethra, both myocytes and ICCs express the channel (Sanders, 2019). ICC-like cells have been identified in human uterus (Duquette et al., 2005), but their role in uterine contractile activity is still unclear. A third of rat myometrial SM cells express an $\mathrm{I}_{\mathrm{ClCa}}$ (Jones et al. Pusch, 2004): but are these then the myometrial pacemaker cells? As mentioned above, ICC-like cells have also been identified in portal vein (Povstyan et al., 2003; Huang et al., 2010), but since both the ICC and SMC generate spontaneous rhythmic inward currents, it is not clear exactly where the pacemaker activity lies. It is interesting however that $\mathrm{I}_{\mathrm{ClCa}}$ is confined to $40 \%$ of portal vein myocytes (Greenwood et al., 2001), a similar number to myometrium, whereas the majority of cells in tonic vessels expresses $\mathrm{I}_{\mathrm{CICa}}$.

Most VSM express both the classical $\mathrm{I}_{\mathrm{ClCa}}$ (mediated by TMEM16A) and a cGMP-dependent $\mathrm{I}_{\mathrm{Cl}(\mathrm{cGMP}, \mathrm{Ca})}$ (mediated by BEST-3). So far myometrium has also been shown to express the classical $\mathrm{I}_{\mathrm{ClCa}}$ (TMEM16A) and although BEST-1 is expressed, BEST-3 and $\mathrm{I}_{\mathrm{Cl}(\mathrm{cGMP}, \mathrm{Ca})}$ have not yet been identified.

Although the data are far from exhaustive or always in agreement, we consider that CaCCs cannot explain the differences in electrical activity and hence contraction, between different smooth muscles.

\section{CONCLUSION AND FUTURE DIRECTIONS}

Calcium-activated chloride channels are an important aspect of SMC physiology, particularly their contribution to excitation and regulation of contraction. Targeting them pharmacologically to modulate their activity is an attractive goal and may aid treatment of several SMC disorders including preterm labour and hypertension. The identification of TMEM16A as the channel-forming protein has enabled deeper insight into their role and expression in several SMCs and in different species, which has brought us somewhat closer to achieving this aim. However, as we have discussed, differences in their role (e.g. whether CaCCs participate in initial depolarisations and AP generation), 
their activation (e.g. from L-type entry as seen in uterus, or SR $\mathrm{Ca}^{2+}$ release, or both as seen in VSMs) and their regulation exist between different SMs and between species, so we cannot simply extrapolate or generalise findings. The non-specificity of classical CaCC inhibitors was problematic for many years, but the recent development of more selective inhibitors should aid the ongoing elucidation of the role of $\mathrm{CaCC}$ in smooth muscles. The role of TMEM16A splice variants and their effect on function needs further elucidating and appears not to have been examined in the myometrium. That TMEM16A mutations are associated with a range of pathologies is also interesting and may point towards future pharmacogenetic profiling or personalised medicine approaches.

The localisation of CaCCs to intracellular membranes including the SR is interesting given the repertoire of $\mathrm{Ca}^{2+}$ release channels present and begs more questions into their role there. Could SR TMEM16A interfere with the function of these $\mathrm{Ca}^{2+}$-release channels? Could they provide a counter

\section{REFERENCES}

Akbarali, H. I., and Giles, W. R. (1993). Ca2+ and Ca(2+)-activated Cl- currents in rabbit oesophageal smooth muscle. J. Physiol. 460, 117-133. doi: 10.1113/ jphysiol.1993.sp019462

Alotaibi, M., Arrowsmith, S., and Wray, S. (2015). Hypoxia-induced force increase (HIFI) is a novel mechanism underlying the strengthening of labor contractions, produced by hypoxic stresses. Proc. Natl. Acad. Sci. U. S. A. 112, 9763-9768. doi: 10.1073/pnas.1503497112

Angermann, J. E., Forrest, A. S., Greenwood, I. A., and Leblanc, N. (2012). Activation of $\mathrm{Ca} 2+-$ activated $\mathrm{Cl}-$ channels by store-operated $\mathrm{Ca} 2+$ entry in arterial smooth muscle cells does not require reverse-mode $\mathrm{Na}+\mathrm{Ca} 2+$ exchange. Can. J. Physiol. Pharmacol. 90, 903-921. doi: 10.1139/y2012-081

Arnaudeau, S., Lepretre, N., and Mironneau, J. (1994). Chloride and monovalent ion-selective cation currents activated by oxytocin in pregnant rat myometrial cells. Am. J. Obstet. Gynecol. 171, 491-501. doi: 10.1016/0002-9378(94) 90288-7

Arreola, J., and Hartzell, H. C. (2019). Wasted TMEM16A channels are rescued by phosphatidylinositol 4,5-bisphosphate. Cell Calcium 84:102103. doi: 10.1016/j. ceca.2019.102103

Atia, J., Mccloskey, C., Shmygol, A. S., Rand, D. A., Van den Berg, H. A., and Blanks, A. M. (2016). Reconstruction of cell surface densities of ion pumps, exchangers, and channels from mRNA expression, conductance kinetics, whole-cell calcium, and current-clamp voltage recordings, with an application to human uterine smooth muscle cells. PLoS Comput. Biol. 12:e1004828. doi: 10.1371/journal.pcbi.1004828

Ayon, R., Sones, W., Forrest, A. S., Wiwchar, M., Valencik, M. L., Sanguinetti, A. R., et al. (2009). Complex phosphatase regulation of Ca2+-activated Cl- currents in pulmonary arterial smooth muscle cells. J. Biol. Chem. 284, 32507-32521. doi: $10.1074 /$ jbc.M109.050401

Bernstein, K., Vink, J. Y., Fu, X. W., Wakita, H., Danielsson, J., Wapner, R., et al. (2014). Calcium-activated chloride channels anoctamin 1 and 2 promote murine uterine smooth muscle contractility. Am. J. Obstet. Gynecol. 211, 688.e1-688.e10. doi: 10.1016/j.ajog.2014.06.018

Bijos, D. A., Drake, M. J., and Vahabi, B. (2014). Anoctamin-1 in the juvenile rat urinary bladder. PLoS One 9:e106190. doi: 10.1371/journal.pone.0106190

Boedtkjer, D. M., Matchkov, V. V., Boedtkjer, E., Nilsson, H., and Aalkjaer, C. (2008). Vasomotion has chloride-dependency in rat mesenteric small arteries. Pflugers Arch. 457, 389-404. doi: 10.1007/s00424-008-0532-3

Broegger, T., Jacobsen, J. C., Secher Dam, V., Boedtkjer, D. M., Kold-Petersen, H., Pedersen, F. S., et al. (2011). Bestrophin is important for the rhythmic but not the tonic contraction in rat mesenteric small arteries. Cardiovasc. Res. 91, 685-693. doi: $10.1093 / \mathrm{cvr} / \mathrm{cvr} 111$ current to $\mathrm{SR} \mathrm{Ca}^{2+}$ release and/or determine the rate of cytosolic $\mathrm{Ca}^{2+}$ increase? Further work is also needed to determine their involvement and interaction with other signalling proteins and channels within membrane microdomains, as well as understanding more about how endogenous modulators or changes to the extracellular milieu can regulate their function.

\section{AUTHOR CONTRIBUTIONS}

SW, CP, and SA contributed equally to the writing of the manuscript and have approved the submitted version.

\section{FUNDING}

This work was supported by the University of Liverpool and the Manchester Metropolitan University should be credited as funders.

Brunner, J. D., Lim, N. K., Schenck, S., Duerst, A., and Dutzler, R. (2014). $\mathrm{X}$-ray structure of a calcium-activated TMEM16 lipid scramblase. Nature 516, 207-212. doi: 10.1038/nature13984

Bulley, S., Neeb, Z. P., Burris, S. K., Bannister, J. P., Thomas-Gatewood, C. M., Jangsangthong, W., et al. (2012). TMEM16A/ANO1 channels contribute to the myogenic response in cerebral arteries. Circ. Res. 111, 1027-1036. doi: 10.1161/CIRCRESAHA.112.277145

Burdyga, T., Borisova, L., Burdyga, A. T., and Wray, S. (2009). Temporal and spatial variations in spontaneous $\mathrm{Ca}$ events and mechanical activity in pregnant rat myometrium. Eur. J. Obstet. Gynecol. Reprod. Biol. 144 (Suppl. 1), S25-S32. doi: 10.1016/j.ejogrb.2009.02.017

Burdyga, T., Wray, S., and Noble, K. (2007). In situ calcium signaling: no calcium sparks detected in rat myometrium. Ann. N. Y. Acad. Sci. 1101, 85-96. doi: 10.1196/annals.1389.002

Burt, R. P. (2003). Phasic contractions of the rat portal vein depend on intracellular Ca2+ release stimulated by depolarization. Am. J. Physiol. Heart Circ. Physiol. 284, H1808-H1817. doi: 10.1152/ajpheart.00637.2002

Byrne, N. G., and Large, W. A. (1987). Action of noradrenaline on single smooth muscle cells freshly dispersed from the rat anococcygeus muscle. J. Physiol. 389, 513-525. doi: 10.1113/jphysiol.1987.sp016669

Byrne, N. G., and Large, W. A. (1988). Membrane ionic mechanisms activated by noradrenaline in cells isolated from the rabbit portal vein. J. Physiol. 404, 557-573. doi: 10.1113/jphysiol.1988.sp017306

Caputo, A., Caci, E., Ferrera, L., Pedemonte, N., Barsanti, C., Sondo, E., et al. (2008). TMEM16A, a membrane protein associated with calcium-dependent chloride channel activity. Science 322, 590-594. doi: 10.1126/science.1163518

Cil, O., Chen, X., Askew Page, H. R., Baldwin, S. N., Jordan, M. C., Myat Thwe, P., et al. (2021). A small molecule inhibitor of the chloride channel TMEM16A blocks vascular smooth muscle contraction and lowers blood pressure in spontaneously hypertensive rats. Kidney Int. 100, 311-320. doi: 10.1016/j.kint.2021.03.025

Coleman, H. A., and Parkington, H. C. (1987). Single channel Cl- and K+ currents from cells of uterus not treated with enzymes. Pflugers Arch. 410, 560-562. doi: 10.1007/BF00586540

Criddle, D. N., de Moura, R. S., Greenwood, I. A., and Large, W. A. (1996). Effect of niflumic acid on noradrenaline-induced contractions of the rat aorta. Br. J. Pharmacol. 118, 1065-1071. doi: 10.1111/j.1476-5381.1996.tb15507.x

Criddle, D. N., de Moura, R. S., Greenwood, I. A., and Large, W. A. (1997). Inhibitory action of niflumic acid on noradrenaline- and 5-hydroxytryptamineinduced pressor responses in the isolated mesenteric vascular bed of the rat. Br. J. Pharmacol. 120, 813-818. doi: 10.1038/sj.bjp.0700981

Cruz-Rangel, S., de Jesus-Perez, J. J., Arechiga-Figueroa, I. A., Rodriguez-Menchaca, A. A., Perez-Cornejo, P., Hartzell, H. C., et al. (2017) 
Extracellular protons enable activation of the calcium-dependent chloride channel TMEM16A. J. Physiol. 595, 1515-1531. doi: 10.1113/JP273111

Dabertrand, F., Fritz, N., Mironneau, J., Macrez, N., and Morel, J. L. (2007). Role of RYR3 splice variants in calcium signaling in mouse nonpregnant and pregnant myometrium. Am. J. Phys. Cell Physiol. 293, C848-C854. doi: 10.1152/ajpcell.00069.2007

Dam, V. S., Boedtkjer, D. M., Nyvad, J., Aalkjaer, C., and Matchkov, V. (2014). TMEM16A knockdown abrogates two different $\mathrm{Ca}(2+)$-activated $\mathrm{Cl}(-)$ currents and contractility of smooth muscle in rat mesenteric small arteries. Pflugers Arch. 466, 1391-1409. doi: 10.1007/s00424-013-1382-1

Dang, S., Feng, S., Tien, J., Peters, C. J., Bulkley, D., Lolicato, M., et al. (2017). Cryo-EM structures of the TMEM16A calcium-activated chloride channel. Nature 552, 426-429. doi: 10.1038/nature25024

Danielsson, J., Perez-Zoghbi, J., Bernstein, K., Barajas, M. B., Zhang, Y., Kumar, S., et al. (2015). Antagonists of the TMEM16A calcium-activated chloride channel modulate airway smooth muscle tone and intracellular calcium. Anesthesiology 123, 569-581. doi: 10.1097/ALN.0000000000000769

Danielsson, J., Vink, J., Hyuga, S., Fu, X. W., Funayama, H., Wapner, R., et al. (2018). Anoctamin channels in human myometrium: a novel target for Tocolysis. Reprod. Sci. 25, 1589-1600. doi: 10.1177/1933719118757683

Davis, A. J., Forrest, A. S., Jepps, T. A., Valencik, M. L., Wiwchar, M., Singer, C. A., et al. (2010). Expression profile and protein translation of TMEM16A in murine smooth muscle. Am. J. Phys. Cell Physiol. 299, C948-C959. doi: 10.1152/ajpcell.00018.2010

Davis, A. J., Shi, J., Pritchard, H. A., Chadha, P. S., Leblanc, N., Vasilikostas, G., et al. (2013). Potent vasorelaxant activity of the TMEM16A inhibitor T16A(inh) -A01. Br. J. Pharmacol. 168, 773-784. doi: 10.1111/j.1476-5381.2012.02199.x

Doughty, J. M., and Langton, P. D. (2001). Measurement of chloride flux associated with the myogenic response in rat cerebral arteries. J. Physiol. 534, 753-761. doi: 10.1111/j.1469-7793.2001.t01-1-00753.x

Drumm, B. T., Rembetski, B. E., Cobine, C. A., Baker, S. A., Sergeant, G. P., Hollywood, M. A., et al. (2018). Ca(2+) signalling in mouse urethral smooth muscle in situ: role of $\mathrm{Ca}(2+)$ stores and $\mathrm{Ca}(2+)$ influx mechanisms. J. Physiol. 596, 1433-1466. doi: 10.1113/JP275719

Drumm, B. T., Thornbury, K. D., Hollywood, M. A., and Sergeant, G. P. (2021). Role of Anol $\mathrm{Ca}(2+)$-activated $\mathrm{Cl}(-)$ channels in generating urethral tone. Am. J. Physiol. Ren. Physiol. 320, F525-F536. doi: 10.1152/ ajprenal.00520.2020

Duquette, R. A., Shmygol, A., Vaillant, C., Mobasheri, A., Pope, M., Burdyga, T., et al. (2005). Vimentin-positive, c-kit-negative interstitial cells in human and rat uterus: a role in pacemaking? Biol. Reprod. 72, 276-283. doi: 10.1095/ biolreprod.104.033506

Fallah, G., Romer, T., Detro-Dassen, S., Braam, U., Markwardt, F., and Schmalzing, G. (2011). TMEM16A(a)/anoctamin-1 shares a homodimeric architecture with CLC chloride channels. Mol. Cell. Proteomics 10:M110.004697. doi: $10.1074 /$ mcp.M110.004697

Falzone, M. E., Malvezzi, M., Lee, B. C., and Accardi, A. (2018). Known structures and unknown mechanisms of TMEM16 scramblases and channels. J. Gen. Physiol. 150, 933-947. doi: 10.1085/jgp.201711957

Ferrera, L., Caputo, A., Ubby, I., Bussani, E., Zegarra-Moran, O., Ravazzolo, R., et al. (2009). Regulation of TMEM16A chloride channel properties by alternative splicing. J. Biol. Chem. 284, 33360-33368. doi: 10.1074/jbc.M109.046607

Ferrera, L., Scudieri, P., Sondo, E., Caputo, A., Caci, E., Zegarra-Moran, O., et al. (2011). A minimal isoform of the TMEM16A protein associated with chloride channel activity. Biochim. Biophys. Acta 1808, 2214-2223. doi: 10.1016/j.bbamem.2011.05.017

Forrest, A. S., Angermann, J. E., Raghunathan, R., Lachendro, C., Greenwood, I. A., and Leblanc, N. (2010). Intricate interaction between store-operated calcium entry and calcium-activated chloride channels in pulmonary artery smooth muscle cells. Adv. Exp. Med. Biol. 661, 31-55. doi: 10.1007/978-1-60761-500-2_3

Forrest, A. S., Joyce, T. C., Huebner, M. L., Ayon, R. J., Wiwchar, M., Joyce, J., et al. (2012). Increased TMEM16A-encoded calcium-activated chloride channel activity is associated with pulmonary hypertension. Am. J. Phys. Cell Physiol. 303, C1229-C1243. doi: 10.1152/ajpcell.00044.2012

Gallos, G., Remy, K. E., Danielsson, J., Funayama, H., Fu, X. W., Chang, H. Y., et al. (2013). Functional expression of the TMEM16 family of calciumactivated chloride channels in airway smooth muscle. Am. J. Physiol. Lung Cell. Mol. Physiol. 305, L625-L634. doi: 10.1152/ajplung.00068.2013
Gordienko, D. V., Clausen, C., and Goligorsky, M. S. (1994). Ionic currents and endothelin signaling in smooth muscle cells from rat renal resistance arteries. Am. J. Phys. 266, F325-F341. doi: 10.1152/ajprenal.1994.266.2.F325

Greenwood, I. A., Hogg, R. C., and Large, W. A. (1995). Effect of frusemide, ethacrynic acid and indanyloxyacetic acid on spontaneous Ca-activated currents in rabbit portal vein smooth muscle cells. Br. J. Pharmacol. 115, 733-738. doi: 10.1111/j.1476-5381.1995.tb14994.x

Greenwood, I. A., and Large, W. A. (1996). Analysis of the time course of calcium-activated chloride "tail" currents in rabbit portal vein smooth muscle cells. Pflugers Arch. 432, 970-979. doi: 10.1007/s004240050224

Greenwood, I. A., and Leblanc, N. (2007). Overlapping pharmacology of Ca2+activated $\mathrm{Cl}-$ and $\mathrm{K}+$ channels. Trends Pharmacol. Sci. 28, 1-5. doi: 10.1016/j. tips.2006.11.004

Greenwood, I. A., Ledoux, J., and Leblanc, N. (2001). Differential regulation of $\mathrm{Ca}(2+)$-activated $\mathrm{Cl}(-)$ currents in rabbit arterial and portal vein smooth muscle cells by $\mathrm{Ca}(2+)$-calmodulin-dependent kinase. J. Physiol. 534, 395408. doi: 10.1111/j.1469-7793.2001.00395.x

Grubb, S., Poulsen, K. A., Juul, C. A., Kyed, T., Klausen, T. K., Larsen, E. H., et al. (2013). TMEM16F (Anoctamin 6), an anion channel of delayed $\mathrm{Ca}(2+)$ activation. J. Gen. Physiol. 141, 585-600. doi: 10.1085/jgp.201210861

Heinze, C., Seniuk, A., Sokolov, M. V., Huebner, A. K., Klementowicz, A. E., Szijarto, I. A., et al. (2014). Disruption of vascular Ca2+-activated chloride currents lowers blood pressure. J. Clin. Invest. 124, 675-686. doi: 10.1172/ JCI70025

Helliwell, R. M., Wang, Q., Hogg, R. C., and Large, W. A. (1994). Synergistic action of histamine and adenosine triphosphate on the response to noradrenaline in rabbit pulmonary artery smooth muscle cells. Pflugers Arch. 426, 433-439. doi: 10.1007/BF00388307

Huang, X., Zhao, D., Wang, Z. Y., Zhang, M. L., Yan, Z. Q., Han, Y. F., et al. (2010). The properties of spontaneous transient inward currents of interstitial cells in rabbit portal vein. Eur. J. Pharmacol. 643, 63-69. doi: 10.1016/j. ejphar.2010.06.011

Hunziker, M., O'donnell, A. M., Gosemann, J., Alvarez, L. A., and Puri, P. (2020). Altered anoctamin-1 and tyrosine phosphorylation in congenital ureteropelvic junction obstruction. J. Pediatr. Surg. 55, 1621-1625. doi: 10.1016/j.jpedsurg.2020.02.001

Hyuga, S., Danielsson, J., Vink, J., Fu, X. W., Wapner, R., and Gallos, G. (2018). Functional comparison of anoctamin 1 antagonists on human uterine smooth muscle contractility and excitability. J. Smooth Muscle Res. 54, 28-42. doi: $10.1540 /$ jsmr.54.28

Iqbal, J., Tonta, M. A., Mitsui, R., Li, Q., Kett, M., Li, J., et al. (2012). Potassium and ANO1/TMEM16A chloride channel profiles distinguish atypical and typical smooth muscle cells from interstitial cells in the mouse renal pelvis. Br. J. Pharmacol. 165, 2389-2408. doi: 10.1111/j.14765381.2011.01730.x

Janssen, L. J., and Sims, S. M. (1992). Acetylcholine activates non-selective cation and chloride conductances in canine and Guinea-pig tracheal myocytes. J. Physiol. 453, 197-218. doi: 10.1113/jphysiol.1992.sp019224

Jeng, G., Aggarwal, M., Yu, W. P., and Chen, T. Y. (2016). Independent activation of distinct pores in dimeric TMEM16A channels. J. Gen. Physiol. 148, 393-404. doi: 10.1085/jgp.201611651

Jensen, A. B., Joergensen, H. B., Dam, V. S., Kamaev, D., Boedtkjer, D., Fuchtbauer, E. M., et al. (2018). Variable contribution of TMEM16A to tone in murine arterial vasculature. Basic Clin. Pharmacol. Toxicol. 123, 30-41. doi: 10.1111/bcpt.12984

Jones, K., Shmygol, A., Kupittayanant, S., and Wray, S. (2004). Electrophysiological characterization and functional importance of calcium-activated chloride channel in rat uterine myocytes. Pflugers Arch. 448, 36-43. doi: 10.1007/ s00424-003-1224-7

Kajioka, S., Nakayama, S., Mccoy, R., Mcmurray, G., Abe, K., and Brading, A. F. (2004). Inward current oscillation underlying tonic contraction caused via ETA receptors in pig detrusor smooth muscle. Am. J. Physiol. Ren. Physiol. 286, F77-F85. doi: 10.1152/ajprenal.00355.2002

Kalienkova, V., Clerico Mosina, V., and Paulino, C. (2021). The groovy TMEM16 family: molecular mechanisms of lipid scrambling and ion conduction. $J$. Mol. Biol. 433:166941. doi: 10.1016/j.jmb.2021.166941

Kamouchi, M., Ogata, R., Fujishima, M., Ito, Y., and Kitamura, K. (1997). Membrane currents evoked by histamine in rabbit basilar artery. Am. J. Phys. 272, H638-H647. doi: 10.1152/ajpheart.1997.272.2.H638 
Kaya, T., Guvenal, T., Karadas, B., Cetin, A., and Soydan, A. S. (2002). Effects of 5-nitro-2-(3-phenylpropylamino) benzoic acid, anthracene-9-carboxylate, and zaprinast on endothelin-1-induced contractions of pregnant rat myometrium. Eur. J. Obstet. Gynecol. Reprod. Biol. 105, 114-119. doi: 10.1016/ S0301-2115(02)00149-5

Kim, H., Kim, H., Lee, J., Lee, B., Kim, H. R., Jung, J., et al. (2018). Anoctamin 9/TMEM16J is a cation channel activated by cAMP/PKA signal. Cell Calcium 71, 75-85. doi: 10.1016/j.ceca.2017.12.003

Klockner, U., and Isenberg, G. (1991). Endothelin depolarizes myocytes from porcine coronary and human mesenteric arteries through a Ca-activated chloride current. Pflugers Arch. 418, 168-175. doi: 10.1007/BF00370467

Ko, W., Jung, S. R., Kim, K. W., Yeon, J. H., Park, C. G., Nam, J. H., et al. (2020). Allosteric modulation of alternatively spliced $\mathrm{Ca}(2+)$-activated $\mathrm{Cl}(-)$ channels TMEM16A by PI(4,5)P2 and CaMKII. Proc. Natl. Acad. Sci. U. S. A. 117, 30787-30798. doi: 10.1073/pnas.2014520117

Kotlikoff, M. I., and Wang, Y. X. (1998). Calcium release and calcium-activated chloride channels in airway smooth muscle cells. Am. J. Respir. Crit. Care Med. 158, S109-S114. doi: 10.1164/ajrccm.158.supplement_2.13tac600

Lamb, F. S., Volk, K. A., and Shibata, E. F. (1994). Calcium-activated chloride current in rabbit coronary artery myocytes. Circ. Res. 75, 742-750. doi: 10.1161/01.RES.75.4.742

Larcombe-Mcdouall, J., Buttell, N., Harrison, N., and Wray, S. (1999). In vivo $\mathrm{pH}$ and metabolite changes during a single contraction in rat uterine smooth muscle. J. Physiol. 518, 783-790. doi: 10.1111/j.1469-7793.1999.0783p.x

Large, W. A., and Wang, Q. (1996). Characteristics and physiological role of the $\mathrm{Ca}(2+)$-activated $\mathrm{Cl}$ - conductance in smooth muscle. Am. J. Phys. 271, C435-C454. doi: 10.1152/ajpcell.1996.271.2.C435

Le, S. C., Jia, Z., Chen, J., and Yang, H. (2019). Molecular basis of PIP2dependent regulation of the $\mathrm{ca}(2+)$-activated chloride channel TMEM16A. Nat. Commun. 10:3769. doi: 10.1038/s41467-019-11784-8

Leblanc, N., and Leung, P. M. (1995). Indirect stimulation of $\mathrm{Ca}(2+)$-activated Cl- current by $\mathrm{Na}+/ \mathrm{Ca} 2+$ exchange in rabbit portal vein smooth muscle. Am. J. Phys. 268, H1906-H1917. doi: 10.1152/ajpheart.1995.268.5.H1906

Ledoux, J., Greenwood, I., Villeneuve, L. R., and Leblanc, N. (2003). Modulation of $\mathrm{Ca} 2+-$ dependent $\mathrm{Cl}$ - channels by calcineurin in rabbit coronary arterial myocytes. J. Physiol. 552, 701-714. doi: 10.1113/jphysiol.2003.043836

Lim, N. K., Lam, A. K., and Dutzler, R. (2016). Independent activation of ion conduction pores in the double-barreled calcium-activated chloride channel TMEM16A. J. Gen. Physiol. 148, 375-392. doi: 10.1085/jgp.201611650

Lin, H., Roh, J., Woo, J. H., Kim, S. J., and Nam, J. H. (2018). TMEM16F/ ANO6, a $\mathrm{Ca}(2+)$-activated anion channel, is negatively regulated by the actin cytoskeleton and intracellular MgATP. Biochem. Biophys. Res. Commun. 503, 2348-2354. doi: 10.1016/j.bbrc.2018.06.160

Manoury, B., Tamuleviciute, A., and Tammaro, P. (2010). TMEM16A/anoctamin 1 protein mediates calcium-activated chloride currents in pulmonary arterial smooth muscle cells. J. Physiol. 588, 2305-2314. doi: 10.1113/ jphysiol.2010.189506

Matchkov, V. V., Aalkjaer, C., and Nilsson, H. (2005). Distribution of cGMPdependent and cGMP-independent $\mathrm{Ca}(2+)$-activated $\mathrm{Cl}(-)$ conductances in smooth muscle cells from different vascular beds and colon. Pflugers Arch. 451, 371-379. doi: 10.1007/s00424-005-1472-9

Matchkov, V. V., Black Joergensen, H., Kamaev, D., Hoegh Jensen, A., Beck, H. C., Skryabin, B. V., et al. (2020). A paradoxical increase of force development in saphenous and tail arteries from heterozygous ANO1 knockout mice. Physiol. Rep. 8:e14645. doi: 10.14814/phy2.14645

Matchkov, V. V., Larsen, P., Bouzinova, E. V., Rojek, A., Boedtkjer, D. M., Golubinskaya, V., et al. (2008). Bestrophin-3 (vitelliform macular dystrophy 2-like 3 protein) is essential for the cGMP-dependent calcium-activated chloride conductance in vascular smooth muscle cells. Circ. Res. 103, 864872. doi: 10.1161/CIRCRESAHA.108.178517

Matchkov, V. V., Secher Dam, V., Bodtkjer, D. M., and Aalkjaer, C. (2013). Transport and function of chloride in vascular smooth muscles. J. Vasc. Res. 50, 69-87. doi: 10.1159/000345242

Mijuskovic, A., Kokic, A. N., Dusic, Z. O., Slavic, M., Spasic, M. B., and Blagojevic, D. (2015). Chloride channels mediate sodium sulphide-induced relaxation in rat uteri. Br. J. Pharmacol. 172, 3671-3686. doi: 10.1111/ bph.13161

Milenkovic, V. M., Krejcova, S., Reichhart, N., Wagner, A., and Strauss, O. (2011). Interaction of bestrophin-1 and $\mathrm{Ca} 2+$ channel beta-subunits: identification of new binding domains on the bestrophin-1 C-terminus. PLoS One 6:e19364. doi: 10.1371/journal.pone.0019364

Nelson, M. T., Cheng, H., Rubart, M., Santana, L. F., Bonev, A. D., Knot, H. J., et al. (1995). Relaxation of arterial smooth muscle by calcium sparks. Science 270, 633-637. doi: 10.1126/science.270.5236.633

Nelson, M. T., Conway, M. A., Knot, H. J., and Brayden, J. E. (1997). Chloride channel blockers inhibit myogenic tone in rat cerebral arteries. J. Physiol. 502, 259-264. doi: 10.1111/j.1469-7793.1997.259bk.x

Ohshiro, J., Yamamura, H., Saeki, T., Suzuki, Y., and Imaizumi, Y. (2014). The multiple expression of $\mathrm{Ca}(2)(+)$-activated $\mathrm{Cl}(-)$ channels via homo- and hetero-dimer formation of TMEM16A splicing variants in murine portal vein. Biochem. Biophys. Res. Commun. 443, 518-523. doi: 10.1016/j. bbrc.2013.11.117

Papp, R., Nagaraj, C., Zabini, D., Nagy, B. M., Lengyel, M., Skofic Maurer, D., et al. (2019). Targeting TMEM16A to reverse vasoconstriction and remodelling in idiopathic pulmonary arterial hypertension. Eur. Respir. J. 53:1800965. doi: 10.1183/13993003.00965-2018

Parkington, H. C., Tonta, M. A., Brennecke, S. P., and Coleman, H. A. (1999). Contractile activity, membrane potential, and cytoplasmic calcium in human uterine smooth muscle in the third trimester of pregnancy and during labor. Am. J. Obstet. Gynecol. 181, 1445-1451. doi: 10.1016/ S0002-9378(99)70390-X

Paulino, C., Kalienkova, V., Lam, A. K. M., Neldner, Y., and Dutzler, R. (2017a). Activation mechanism of the calcium-activated chloride channel TMEM16A revealed by cryo-EM. Nature 552, 421-425. doi: 10.1038/ nature 24652

Paulino, C., Neldner, Y., Lam, A. K., Kalienkova, V., Brunner, J. D., Schenck, S., et al. (2017b). Structural basis for anion conduction in the calcium-activated chloride channel TMEM16A. elife 6:e26232. doi: 10.7554/eLife.26232

Pedemonte, N., and Galietta, L. J. (2014). Structure and function of TMEM16 proteins (anoctamins). Physiol. Rev. 94, 419-459. doi: 10.1152/ physrev.00039.2011

Peters, C. J., Gilchrist, J. M., Tien, J., Bethel, N. P., Qi, L., Chen, T., et al. (2018). The sixth transmembrane segment is a major gating component of the TMEM16A calcium-activated Chloride Channel. Neuron 97, 1063.e4-1077. e4. doi: 10.1016/j.neuron.2018.01.048

Picollo, A., Malvezzi, M., and Accardi, A. (2015). TMEM16 proteins: unknown structure and confusing functions. J. Mol. Biol. 427, 94-105. doi: 10.1016/j. jmb.2014.09.028

Pierce, S. J., Kupittayanant, S., Shmygol, T., and Wray, S. (2003). The effects of $\mathrm{pH}$ change on $\mathrm{Ca}(++)$ signaling and force in pregnant human myometrium Am. J. Obstet. Gynecol. 188, 1031-1038. doi: 10.1067/mob.2003.229

Povstyan, O. V., Gordienko, D. V., Harhun, M. I., and Bolton, T. B. (2003). Identification of interstitial cells of Cajal in the rabbit portal vein. Cell Calcium 33, 223-239. doi: 10.1016/S0143-4160(02)00197-5

Pritchard, H. A., Leblanc, N., Albert, A. P., and Greenwood, I. A. (2014). Inhibitory role of phosphatidylinositol 4,5-bisphosphate on TMEM16A-encoded calcium-activated chloride channels in rat pulmonary artery. Br. J. Pharmacol. 171, 4311-4321. doi: 10.1111/bph.12778

Pusch, M. (2004). Ca(2+)-activated chloride channels go molecular. J. Gen. Physiol. 123, 323-325. doi: 10.1085/jgp.200409053

Qu, M., Lu, P., Bellve, K., Fogarty, K., Lifshitz, L., Shi, F., et al. (2019). Smooth muscle cell-specific TMEM16A deletion does not alter Ca2+ signaling, uterine contraction, gestation length, or litter size in micedagger. Biol. Reprod. 101, 318-327. doi: 10.1093/biolre/ioz096

Reichhart, N., Milenkovic, V. M., Halsband, C. A., Cordeiro, S., and Strauss, O. (2010). Effect of bestrophin-1 on L-type Ca2+ channel activity depends on the Ca2+ channel beta-subunit. Exp. Eye Res. 91, 630-639. doi: 10.1016/j. exer.2010.08.001

Saha, J. K., Sengupta, J. N., and Goyal, R. K. (1992). Role of chloride ions in lower esophageal sphincter tone and relaxation. Am. J. Phys. 263, G115-G126. doi: 10.1152/ajpgi.1992.263.1.G115

Saleh, S. N., and Greenwood, I. A. (2005). Activation of chloride currents in murine portal vein smooth muscle cells by membrane depolarization involves intracellular calcium release. Am. J. Phys. Cell Physiol. 288, C122-C131. doi: 10.1152/ajpcell.00384.2004

Sanders, K. M. (2019). Spontaneous electrical activity and rhythmicity in gastrointestinal smooth muscles. Adv. Exp. Med. Biol. 1124, 3-46. doi: 10.1007/978-981-13-5895-1_1 
Sanders, K. M., Zhu, M. H., Britton, F., Koh, S. D., and Ward, S. M. (2012). Anoctamins and gastrointestinal smooth muscle excitability. Exp. Physiol. 97, 200-206. doi: 10.1113/expphysiol.2011.058248

Schroeder, B. C., Cheng, T., Jan, Y. N., and Jan, L. Y. (2008). Expression cloning of TMEM16A as a calcium-activated chloride channel subunit. Cell 134, 1019-1029. doi: 10.1016/j.cell.2008.09.003

Shimizu, T., Iehara, T., Sato, K., Fujii, T., Sakai, H., and Okada, Y. (2013). TMEM16F is a component of a $\mathrm{Ca} 2+-$ activated $\mathrm{Cl}$ - channel but not a volume-sensitive outwardly rectifying Cl- channel. Am. J. Phys. Cell Physiol. 304, C748-C759. doi: 10.1152/ajpcell.00228.2012

Sones, W. R., Davis, A. J., Leblanc, N., and Greenwood, I. A. (2010). Cholesterol depletion alters amplitude and pharmacology of vascular calcium-activated chloride channels. Cardiovasc. Res. 87, 476-484. doi: $10.1093 / \mathrm{cvr} / \mathrm{cvq} 057$

Sun, H., Xia, Y., Paudel, O., Yang, X. R., and Sham, J. S. (2012). Chronic hypoxia-induced upregulation of $\mathrm{Ca} 2+-$ activated $\mathrm{Cl}$ - channel in pulmonary arterial myocytes: a mechanism contributing to enhanced vasoreactivity. J. Physiol. 590, 3507-3521. doi: 10.1113/jphysiol.2012.232520

Suzuki, J., Fujii, T., Imao, T., Ishihara, K., Kuba, H., and Nagata, S. (2013). Calcium-dependent phospholipid scramblase activity of TMEM16 protein family members. J. Biol. Chem. 288, 13305-13316. doi: 10.1074/jbc. M113.457937

Terashima, H., Picollo, A., and Accardi, A. (2013). Purified TMEM16A is sufficient to form Ca2+-activated Cl- channels. Proc. Natl. Acad. Sci. U. S. A. 110, 19354-19359. doi: 10.1073/pnas.1312014110

Thomas-Gatewood, C., Neeb, Z. P., Bulley, S., Adebiyi, A., Bannister, J. P., Leo, M. D., et al. (2011). TMEM16A channels generate $\mathrm{Ca}(2)(+)$-activated $\mathrm{Cl}(-)$ currents in cerebral artery smooth muscle cells. Am. J. Physiol. Heart Circ. Physiol. 301, H1819-H1827. doi: 10.1152/ajpheart.00404.2011

Van Helden, D. F. (1991). Spontaneous and noradrenaline-induced transient depolarizations in the smooth muscle of Guinea-pig mesenteric vein. J. Physiol. 437, 511-541. doi: 10.1113/jphysiol.1991.sp018609

Wang, Q., Hogg, R. C., and Large, W. A. (1992). Properties of spontaneous inward currents recorded in smooth muscle cells isolated from the rabbit portal vein. J. Physiol. 451, 525-537. doi: 10.1113/jphysiol.1992. sp019177

Wang, Q., Leo, M. D., Narayanan, D., Kuruvilla, K. P., and Jaggar, J. H. (2016). Local coupling of TRPC6 to ANO1/TMEM16A channels in smooth muscle cells amplifies vasoconstriction in cerebral arteries. Am. J. Phys. Cell Physiol. 310, C1001-C1009. doi: 10.1152/ajpcell.00092.2016

Wang, B., Li, C., Huai, R., and Qu, Z. (2015). Overexpression of ANO1/ TMEM16A, an arterial Ca2+-activated Cl- channel, contributes to spontaneous hypertension. J. Mol. Cell. Cardiol. 82, 22-32. doi: 10.1016/j. yjmcc.2015.02.020

Wang, M., Yang, H., Zheng, L. Y., Zhang, Z., Tang, Y. B., Wang, G. L., et al. (2012). Downregulation of TMEM16A calcium-activated chloride channel contributes to cerebrovascular remodeling during hypertension by promoting basilar smooth muscle cell proliferation. Circulation 125, 697-707. doi: 10.1161/CIRCULATIONAHA.111.041806

Wiwchar, M., Ayon, R., Greenwood, I. A., and Leblanc, N. (2009). Phosphorylation alters the pharmacology of $\mathrm{Ca}(2+)$-activated $\mathrm{Cl}$ channels in rabbit pulmonary arterial smooth muscle cells. Br. J. Pharmacol. 158, 1356-1365. doi: 10.1111/j. 1476-5381.2009.00405.x

Wray, S., and Arrowsmith, S. (2021). Uterine excitability and ion channels and their changes with gestation and hormonal environment. Annu. Rev. Physiol. 83, 331-357. doi: 10.1146/annurev-physiol-032420-035509

Wray, S., Burdyga, T., Noble, D., Noble, K., Borysova, L., and Arrowsmith, S. (2015). Progress in understanding electro-mechanical signalling in the myometrium. Acta Physiol. 213, 417-431. doi: 10.1111/apha.12431
Yang, Y. D., Cho, H., Koo, J. Y., Tak, M. H., Cho, Y., Shim, W. S., et al. (2008). TMEM16A confers receptor-activated calcium-dependent chloride conductance. Nature 455, 1210-1215. doi: 10.1038/nature07313

Yang, T., and Colecraft, H. M. (2016). Calmodulin regulation of TMEM16A and $16 \mathrm{~B} \mathrm{Ca}(2+)$-activated chloride channels. Channels 10, 38-44. doi: 10.1080/19336950.2015.1058455

Yang, T., Hendrickson, W. A., and Colecraft, H. M. (2014). Preassociated apocalmodulin mediates $\mathrm{Ca} 2+-$ dependent sensitization of activation and inactivation of TMEM16A/16B Ca2+-gated Cl- channels. Proc. Natl. Acad. Sci. U. S. A. 111, 18213-18218. doi: 10.1073/pnas.1420984111

Yang, H., Kim, A., David, T., Palmer, D., Jin, T., Tien, J., et al. (2012). TMEM16F forms a $\mathrm{Ca} 2+-$ activated cation channel required for lipid scrambling in platelets during blood coagulation. Cell 151, 111-122. doi: 10.1016/j. cell.2012.07.036

Yarar, Y., Cetin, A., and Kaya, T. (2001). Chloride channel blockers 5-nitro-2(3-phenylpropylamino) benzoic acid and anthracene-9-carboxylic acid inhibit contractions of pregnant rat myometrium in vitro. J. Soc. Gynecol. Investig. 8, 206-209. doi: 10.1016/s1071-5576(01)00113-7

Yarotskyy, V., Malysz, J., and Petkov, G. V. (2019). Extracellular pH and intracellular phosphatidylinositol 4,5-bisphosphate control $\mathrm{Cl}(-)$ currents in Guinea pig detrusor smooth muscle cells. Am. J. Phys. Cell Physiol. 317, C1268-C1277. doi: 10.1152/ajpcell.00189.2019

Yip, K. P., Balasubramanian, L., Kan, C., Wang, L., Liu, R., Ribeiro-Silva, L., et al. (2018). Intraluminal pressure triggers myogenic response via activation of calcium spark and calcium-activated chloride channel in rat renal afferent arteriole. Am. J. Physiol. Ren. Physiol. 315, F1592-F1600. doi: 10.1152/ ajprenal.00239.2018

Young, R. C., and Bemis, A. (2009). Calcium-activated chloride currents prolongs the duration of contractions in pregnant rat myometrial tissue. Reprod. Sci. 16, 734-739. doi: 10.1177/1933719109334965

Yuan, X. J. (1997). Role of calcium-activated chloride current in regulating pulmonary vasomotor tone. Am. J. Phys. 272, L959-L968. doi: 10.1152/ ajplung.1997.272.5.L959

Zhang, Y., and Paterson, W. G. (2002). Role of Ca2+-activated Cl- channels and MLCK in slow IJP in opossum esophageal smooth muscle. Am. J. Physiol. Gastrointest. Liver Physiol. 283, G104-G114. doi: 10.1152/ ajpgi.00052.2002

Zhao, Q. Y., Peng, Y. B., Luo, X. J., Luo, X., Xu, H., Wei, M. Y., et al. (2017) Distinct effects of $\mathrm{Ca}(2+)$ Sparks on cerebral artery and airway smooth muscle cell tone in mice and humans. Int. J. Biol. Sci. 13, 1242-1253. doi: $10.7150 /$ ijbs. 21475

Conflict of Interest: The authors declare that the research was conducted in the absence of any commercial or financial relationships that could be construed as a potential conflict of interest.

Publisher's Note: All claims expressed in this article are solely those of the authors and do not necessarily represent those of their affiliated organizations, or those of the publisher, the editors and the reviewers. Any product that may be evaluated in this article, or claim that may be made by its manufacturer, is not guaranteed or endorsed by the publisher.

Copyright (C) 2021 Wray, Prendergast and Arrowsmith. This is an open-access article distributed under the terms of the Creative Commons Attribution License (CC $B Y)$. The use, distribution or reproduction in other forums is permitted, provided the original author(s) and the copyright owner(s) are credited and that the original publication in this journal is cited, in accordance with accepted academic practice. No use, distribution or reproduction is permitted which does not comply with these terms. 